Michael J. Griffin MRCPI FFARCSI, Louise Brennan,

Alan J. McShane MRCPI FFARCSI

\title{
Preoperative education and outcome of patient controlled analgesia
}

Purpose: To determine the effect of intensive preoperative education on the outcome of Patient Controlled Analgesia (PCA) postoperatively.

Methods: This prospective randomised study was carried out in a single teaching hospital over three months. One group of patients $(n=42)$ received a 20 min standardised tutorial regarding PCA use from a single investigator and the other group $(n=43)$ received no additional education apart from the routine preoperative anaesthetic consultation. A blinded investigator assessed the patients following surgery. Pain scores and morphine consumption, patient satisfaction, side-effect profile and anti-emetic use were recorded at six, 24 and $48 \mathrm{hr}$ postoperatively.

Results: Pain scores, satisfaction scores and morphine consumption were similar in both groups throughout the study period. Fewer patients in the tutored group complained of nausea from 6 to $24 \mathrm{hr}$ than did untutored patients $(28 \%$ vs $51 \% ; P<0.05)$. More tutored patients used antiemetic medication from 0 to $6(28 \%$ vs $12 \%$; $P<0.05)$ and 6 to $24 \mathrm{hr}(37 \%$ vs 19\%; $P<0.05)$. Side effect profile and requirement for rescue analgesia was otherwise similar in both groups.

Conclusion: Our results suggest that specific preoperative education of patients using PCA does not alter pain scores, morphine consumption or patient satisfaction but may result in earlier and more effective use of anti-emetic medication.

Objectif : Déterminer l'effet d'un enseignement préopératoire intensif sur l'évolution postopératoire de l'analgésie contrôlée par le patient (ACP).

Méthode : On a réalisé une étude prospective et randomisée dans un seul hôpital d'enseignement pendant trois mois. Un groupe de patients $(n=42)$ a reçu d'un unique expérimentateur un cours individuel standardisé concernant l'utilisation de l'ACP et l'autre groupe $(n=43)$ n'a reçu aucun enseignement additionnel après la visite de routine de l'anesthésiste avant l'intervention. Un expérimentateur impartial a évalué les patients après la chirurgie. Les scores de douleur et la consommation de morphine, la satisfaction du patient, le profil des effets secondaires et l'utilisation d'antiémétique ont été enregistrés six, 24 et $48 \mathrm{~h}$ après l'opération.

Résultat : Les scores de douleur et de satisfaction et la consommation de morphine étaient similaires dans les deux groupes tout au long de l'expérience. II y a eu moins de plaintes de nausée entre 6 et $24 \mathrm{~h}$ chez les patients qui ont reçu un enseignement que chez ceux qui n'en ont pas eu ( $28 \%$ vs $51 \% ; P<0,05$ ). Un plus grand nombre de patients informés a utilisé des médicaments antiémétiques de 0 à $6(28 \%$ vs $12 \% ; P<0,05)$ et de 6 à $24 \mathrm{~h}(37 \%$ vs $19 \% ; P<0,05)$. Le profil des effets secondaires et la demande d'analgésie supplémentaire ont été, par ailleurs, similaires dans les deux groupes.

Conclusion : Nos résultats laissent croire qu'un enseignement préopératoire spécifique dispensé aux patients qui utilisent I'ACP n'a pas d'effet sur les scores de douleur, la consommation de morphine ou la satisfaction du patient, mais qu'il peut entraîner un usage précoce et plus efficace de médicaments antiémétiques.

From the Department of Anaesthesia and Intensive Care, St. Vincent's Hospital, Elm Park, Dublin 4, Ireland. Address correspondence to: Dr. M.J. Griffin, Department of Anesthesiology, Yale University School of Medicine, 333 Cedar Street, New Haven, CT 06520-8051, USA. Phone: 203-785-2802; Fax: 203-785-6664; E-mail: michael.griffin@yale.edu Accepted for publication July 29, 1998. 
$\mathrm{P}$ ATIENT Controlled Analgesia (PCA) was first introduced in 1971 and has become one of the most popular methods of administra tion of postoperative analgesia. However, PCA is not universally effective in providing high quality analgesia and patient satisfaction ${ }^{1,2}$ and remains the subject of much debate. ${ }^{3}$ Many patients using PCA obtain inadequate pain relief or have important symptoms which are ascribed to PCA resulting in premature termination and poor results. ${ }^{1}$

Patient participation in medical care can enhance the effectiveness of treatment. ${ }^{4}$ One aspect of the preoperative consultation is discussion of postoperative analgesia and is a forum for patient education. Anxiety and poor coping skills are predictors of postoperative pain and may be improved by education. ${ }^{5}$ General preoperative education may result in reduced patient anxiety, facilitating recovery and earlier patient discharge. However, patient education is usually unplanned and haphazard and poor patient knowledge regarding postoperative analgesia is well documented. ${ }^{6,7}$ There has been little research on the effect of psychological factors and preoperative patient education on the effectiveness and outcome of PCA. ${ }^{8}$ There is little mention of preparatory education given to patients in many studies and most PCA studies fail to mention whether or how they educated patients in the use of PCA. Therefore, there may be considerable potential for improved outcome of PCA with more effective preoperative education.

The purpose of this randomised prospective study was to determine whether intensive specific preoperative education improved the effectiveness of PCA. Effectiveness was determined by measurement of patient pain scores and morphine consumption, patient satisfaction, side-effect profile and anti-emetic use over $48 \mathrm{hr}$ postoperatively.

\section{Methods}

Following hospital ethics committee approval 85 patients admitted for elective surgery were studied. On the evening prior to surgery, patients with no previous experience of PCA and scheduled for major procedures suitable for postoperative PCA, were selected from the operating list. Patients were randomly assigned to one of two groups: one group received a standardised intensive tutorial with regard to PCA use and the other group received a routine preoperative anaesthetic assessment and visit. Written consent was obtained from both groups: the educational group consented to the tutorial, subsequent chart review and postoperative pain and satisfaction score assessments; the control group consented to a chart review and postoperative assessments. The use of pain and satisfaction VAS scoring scales were explained to both groups.

The tutorial, given to the educational group, conducted on the evening prior to surgery, consisted of an explanation of the principles of PCA and a demonstration of the device. The tutorial concentrated on knowledge and coping strategies. The fact that the patients were responsible for their own pain relief was stressed and strategies for maximising pain control were suggested such as prevention of anticipated discomfort, use before sleep and on waking. Fears with regard to safety and possible reduced contact with nursing staff were allayed. Side effects were outlined and the availability of treatment for these stressed. An information sheet outlining the main points was given to the patient at the conclusion of the tutorial which lasted approximately $20 \mathrm{~min}$ (Figure 1). A single investigator administered all of the tutorials and no member of the care team was aware of the patient randomisation status.

Premedication consisted of diazepam as appropriate. Anaesthesia was induced with propofol and muscle relaxation produced with vecuronium to facilitate tracheal intubation. Anaesthesia was maintained with $\mathrm{O}_{2} / \mathrm{N}_{2} \mathrm{O}$ and isoflurane. Fentanyl $1.5 \mu \mathrm{g} \cdot \mathrm{kg}^{-1}$ was administered prior to induction, droperidol $15 \mu \mathrm{g} \cdot \mathrm{kg}^{-1}$ administered after induction and morphine iv administered at the discretion of the anaesthetist during surgery. No local or regional anaesthesia was used. Patients were commenced on PCA in the recovery room. The device used was the Baxter Infusor System with $120 \mathrm{mg}$ morphine in $60 \mathrm{ml}$ saline $0.9 \%$ in the reservoir, delivering a $1 \mathrm{mg}$ bolus with a six minute lockout period. A loading dose was administered as required and total intraoperative morphine and morphine in recovery were recorded and included in the total morphine consumption. Patients were discharged to the ward only when their pain scores were $<4$.

All patients were assessed by a single investigator unaware of their randomisation status. Data was obtained at six, 24 and $48 \mathrm{hr}$ after discharge from the recovery room. Patients were asked to rate their average pain over the preceding time interval with a 100 mm Visual Analogue Scale. In addition, patients were asked to rate their overall level of satisfaction with level of analgesia and side effects. Morphine consumption, side effects, anti-emetic use and requirement for rescue analgesia were noted. Rescue analgesia was defined as analgesia administered above and beyond that available from the PCA use and was administered when patients' demands exceeded the limits of the device. The side effects recorded were respiratory 
depression, anorexia, nausea, vomiting, constipation and pruritus. Any episode of the side effect occurring at any time over the preceding time interval was recorded in a yes/no manner.

Sample size was determined to give the study a power of $80 \%$ to detect a VAS pain score difference of 2 and a difference in morphine consumption of $20 \mathrm{mg}$ per $24 \mathrm{hr}$ between the two groups. Statistical analysis of morphine consumption, pain and satisfaction scores was performed with two way analysis of variance. Discrete data (side effects, antiemetic and rescue analgesia requirements) were compared using Chi- squared analysis and Fisher's exact test for analysis of $2 \times 2$ tables with small frequencies. $P<0.05$ was considered statistically significant.

\section{Results}

The demographics of the groups are demonstrated in Table I. The educational group consisted of 42 patients and the control group of 43 patients. The age, sex and types of surgery performed in both groups were similar. General surgery cases consisted of major intraabdominal procedures, gynaecological cases consisted of total abdominal hysterectomies, urological proce-

\section{PATIENT CONTROLLED ANALGESIA (PCA)}

\section{INDIVIDUALIZED TREATMENT}

Exact individual requirements are met because you, the patient, treats yourself when you need it and as often as you need it. Intramuscular injections may provide sufficient pain relief but may not and may be painful.

\section{YOU'RE IN CONTROL}

One of the big benefits of PCA is the element of control it gives you over your pain. We hope that this will boost your confidence and help speed your recovery.

\section{GREAT FOR SUDDEN OR UNEXPECTED PAIN}

You can deal with this immediately yourself and continue to dose yourself until the pain has been controlled or eased. If at any stage you are not getting adequate pain relief, we have prescribed additional analgesia to supplement the PCA.

\section{GREAT FOR ANTICIPATED DISCOMFORT}

You can press the button some time before, say, getting out of bed, physiotherapy or having a dressing removed and so prevent or minimise pain and discomfort.

\section{PROMOTES HEALING AND RAPID RECOVERY}

Good pain relief minimises stress and this has been shown to have beneficial effects on your heart, to promote healing and help fight infection. PCA also promotes early mobilisation and more rapid recovery.

\section{SAFETY}

The safety of the device rests in the fact that you become drowsy when you have had enough drug and so will not continue to self administer. In addition, there is an in-built automatic "lock-out" period during which the dosing chamber of the device is slowly filling and this prevents a dose being administered too frequently.

\section{SIDE EFFECTS}

All drugs have side effects. These are usually minor but if one knows about them in advance, hopefully they will not cause as much trouble. Decrease in appetite is a common experience in the first days after surgery. This may be due to the surgery or to drug effects. Many drugs used in the time around the operation makes one's bowel movement a little sluggish and this often accounts for the decrease in appetite. Morphine in the PCA also causes this but as it is temporary and is also accompanied by excellent pain control, it is not normally a big problem. Similarly, postoperative nausea and vomiting may be due to the surgery or drug effects. The morphine may initially contribute to the problem, but most patients become tolerant to any such effects after a short while and are able to continue to avail of the excellent pain relief provided by PCA. In addition, as you will be receiving your morphine in small frequent doses, you should be spared the surge in blood levels associated with 4-6 hourly injections and may be less likely to develop severe side effects.

FIGURE 1 Information sheet given to the educational group patients at the end of the tutorial session. 
dures consisted of major open renal surgery and orthopaedic cases were major joint surgeries. Pain scores and satisfaction scores were similar in both groups throughout the study period (Figures 2,3 ).

There was no difference in morphine consumption between the groups throughout the study (Figure 4). Similarly, the requirements for rescue analgesia were similar throughout (Table II). Table II also demonstrates the side effect profile and frequency of antiemetic request in each group. Fewer patients in the educational group complained of nausea from 6 to $24 \mathrm{hr}(28 \%$ vs $51 \%, P<0.05)$. More patients in the educational group used antiemetic medication from 0 to 6 and 6 to $24 \mathrm{hr}(28 \%$ and $37 \%$ respectively, $\mathrm{P}<0.05$ ) than control group patients ( $12 \%$ and $19 \%$ respectively, $P<0.05$ ). Patients in the educational group, therefore, were more likely to demand an antiemetic and tended to demand it earlier than control group patients.

\section{Discussion}

This study set out to determine the effect of intensive preoperative education about PCA on postoperative pain, analgesia requirement, patient satisfaction and side effect profile. Patient Controlled Analgesia was seen to be an effective mode of analgesia administra-

TABLE I Demographic details of and type of surgery performed on the educational and control groups of patients.

\begin{tabular}{llll}
\hline & Educational Group & Control Group \\
\hline Age (mean \pm SD) & $48 \pm-15.6$ & $47 \pm-17.4$ \\
Malc/Female & $15 / 27$ & $10 / 33$ \\
Surgery & General & 18 & 20 \\
& Gynaccological & 12 & 8 \\
& Urological & 3 & 6 \\
& Orthopacdic & 7 & 7 \\
& Miscellaneous & 2 & 2 \\
\hline
\end{tabular}

tion in both groups in terms of pain and satisfaction scores and confirms previous studies. ${ }^{1,9}$ Surprisingly, our tutored group did not demonstrate more liberal use of PCA. Morphine consumption was similar in both groups.

Postoperative pain and satisfaction is complex and multifactorial. Personality traits such as high anxiety level, neuroticism and preference for control predict higher pain scores irrespective of the mode of analgesia. ${ }^{5,9}$ Patients with a high level of anxiety gain most benefit from PCA with the greatest reduction in pain scores. ${ }^{5}$ Some personality traits, such as low preference for control are known to result in unwillingness to use PCA. ${ }^{5}$ The major benefit of preoperative information may derive from it's effect on the patient's perceived

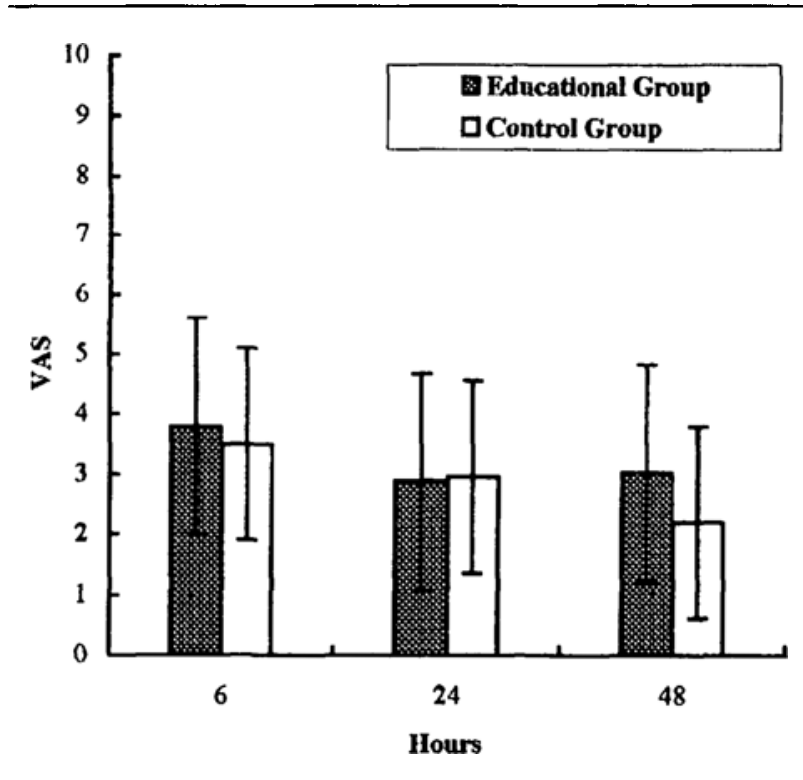

FIGURE 2 Visual Analogue Scale (VAS) pain scores in the educational group and the control group over $48 \mathrm{hr}$ post surgery. Error bars indicate \pm 1 standard deviation.

TABLE II The side effect profile, request for antiemetic medication and requirement for rescue analgesia of both educational and control patient groups over $48 \mathrm{hr}$ after surgery. (Numbers and percentages).

\begin{tabular}{lllllll}
\hline & \multicolumn{3}{c}{$0-6 \mathrm{hr}$} & \multicolumn{2}{c}{$6-24 \mathrm{hr}$} & $24-48 \mathrm{hr}$ \\
& Educational & Control & Educational & Control & Educational & Control \\
\hline Anorexia (\%) & $23(55 \%)$ & $21(49 \%)$ & $19(45 \%)$ & $21(49 \%)$ & $9(21 \%)$ & $8(19 \%)$ \\
Nausea (\%) & $17(40 \%)$ & $16(37 \%)$ & $12(29 \%)^{*}$ & $22(51 \%)$ & $5(12 \%)$ & $6(14 \%)$ \\
Vomiting (\%) & $7(17 \%)$ & $12(28 \%)$ & $10(24 \%)$ & $16(37 \%)$ & $2(5 \%)$ & $3(7 \%)$ \\
Constipation (\%) & $1(2 \%)$ & $0(0 \%)$ & $8(19 \%)$ & $8(19 \%)$ & $7(17 \%)$ & $3(7 \%)$ \\
Pruritus (\%) & $2(5 \%)$ & $3(7 \%)$ & $12(29 \%)$ & $7(16 \%)$ & $7(17 \%)$ & $7(16 \%)$ \\
No SEs (\%) & $1(2 \%)$ & $3(7 \%)$ & $2(5 \%)$ & $6(14 \%)$ & $6(14 \%)$ & $7(16 \%)$ \\
Antienctic use & $12(28 \%)^{*}$ & $5(12 \%)$ & $16(37 \%)^{*}$ & $8(19 \%)$ & $4(10 \%)$ & $1(2 \%)$ \\
Rescue analgesia & $6(14 \%)$ & $4(9 \%)$ & $4(10 \%)$ & $6(14 \%)$ & $5(12 \%)$ & $5(12 \%)$ \\
\hline
\end{tabular}

$*=0.05$ 


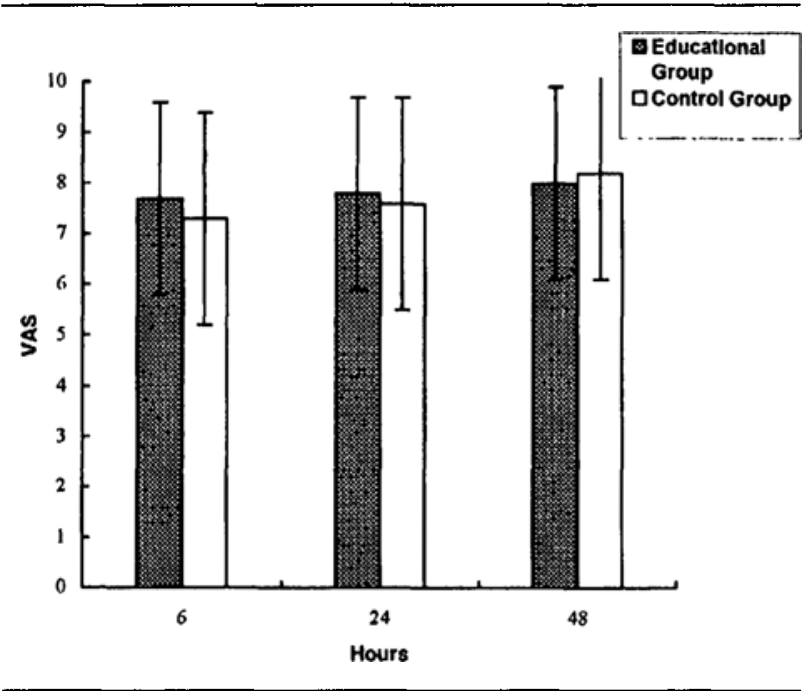

FIGURE 3 Visual Analogue Scale (VAS) satisfaction scores in the educational group and the control group over $48 \mathrm{hr}$ post surgery. Error bars indicate \pm 1 standard deviation.

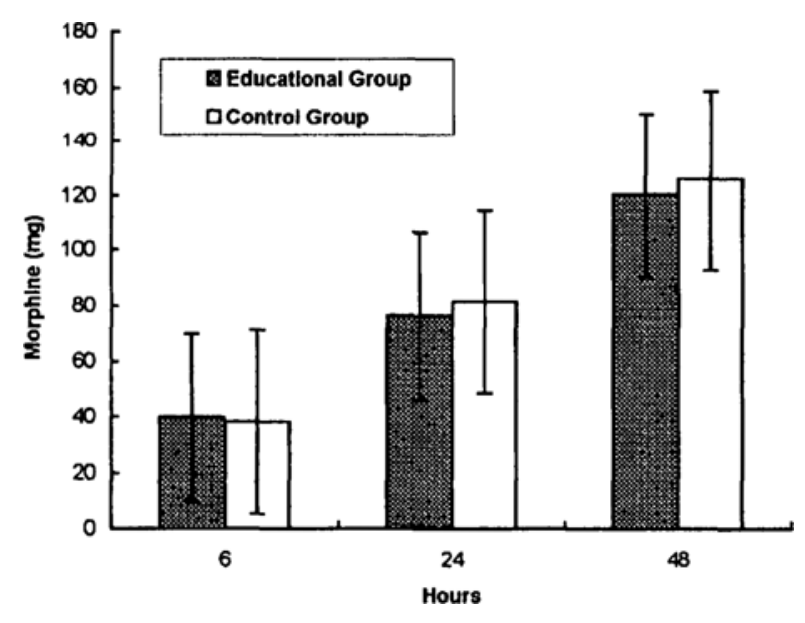

FIGURE 4 Morphine consumption in the educational and the control groups over 48 hr post surgery. Error bars indicate \pm 1 standard deviation.

level of control over his experience. ${ }^{10}$ However, in our study both groups had high satisfaction scores, suggesting that the tutorial did not further improve anxiety levels or perceived level of control. In addition, a number of patient fears may reduce the likely benefit from PCA. ${ }^{2}$ These include the risk of overdose, addiction and the loss of patient-nurse contact. ${ }^{1,11,12}$ Our study, however, suggests that these concerns, if present, were not important in our patient population.

Preoperative education may have a number of effects. Education provides reassurance with regard to patients' fears mentioned above and may improve management of side effects. ${ }^{11,13}$ Education reduces anxiety which contributes to pain and may encourage the autonomy and control that PCA allows. ${ }^{14,15}$ Preoperative education may decrease anxiety and increase patients' ability to participate in recovery. Both intramuscular and PCA studies have demonstrated reduced postoperative pain scores, analgesia demand and increased patient satisfaction following preoperative education programmes. ${ }^{7,13,16}$ However, like others, our study has failed to demonstrate such an impact. ${ }^{10}$ Preoperative tuition may unduly increase expectations in some patients with regard to postoperative pain relief and patients frequently underestimate the level of pain they will experience. ${ }^{14}$ Intense tuition immediately preoperatively may result in increased postoperative anxiety and more basic education at the time of admission may be more effective. ${ }^{17}$ Therefore, the optimum timing and nature of preoperative education has not been determined and probably needs to be tailored to individual patients. ${ }^{11,17}$ A study demonstrating a high correlation between patient satisfaction with the amount of information provided and reduction in anxiety level supports this. ${ }^{18}$

With regard to side effect profile, previous studies have demonstrated an equal incidence of ileus and confusion with $i m$ and PCA morphine administration but there was a strong patient preference for PCA. ${ }^{19}$ Our teaching programme included information regarding potential side effects of PCA and emphasised that these were not specific to the PCA mode of administration. Management and some coping methods were stressed. Informing patients about potential side effects may enhance their recall of them. ${ }^{9}$ Despite this, our tutored group recalled less nausea and vomiting over the initial $24 \mathrm{hr}$ after surgery. Our results suggest that this may be due to earlier and more effective use of anti-emetics by the tutored group presumably due to preoperative advice and encouragement with regard to management. In addition, nursing education with regard to the high incidence of postoperative nausea and vomiting may result in earlier antiemetic uptake, may be more effective and save time and energy in the preoperative period. Recently, the need to avoid nausea and vomiting and fear of overdose have been shown to be a major concern for patients receiving PCA for postoperative analgesia. 20,21

There is an opinion that patient utilisation of PCA may be limited by the presence of side effects with toleration of a degree of pain or that patients may titrate morphine to an "expected" level of pain rather than complete analgesia. ${ }^{22}$ The findings of our study do not support either hypothesis. Firstly, the reduced nausea 
in the tutored group did not result in greater morphine utilisation or lower pain scores. Secondly, education, reassurance and encouragement with regard to PCA use did not result in titration of analgesia to a lower level of pain.

In conclusion, we have demonstrated that preoperative tuition regarding PCA use may result in increased and earlier use of antiemetic medication associated with a modest improvement in side effect profile. Preoperative tuition did not alter pain scores, satisfaction scores and PCA utilisation. It may be possible for anaesthetists and nursing staff to reduce the incidence and severity of postoperative side effects and improve PCA outcome by specifically referring to potential side effects, educating patients with regard to coping skills and to the ready availability of antiemetic medication.

\section{Acknowledgment}

The authors acknowledge grant support from the Health Research Board of Ireland.

\section{References}

1 Notcutt WG, Morgan RJM. Introducing patient-controlled analgesia for postoperative pain control into a district general hospital. Anaesthesia 1990; 45: 401-6.

2 Murphy DF, Grazioti G, Chalkiadis G, McKenna $M$. Proceedings of the 7 th World Congress on Pain, Seattle: Internatational Association Study of Pain 1993; 393.

3 Hall GM, Salmon P. Patient-controlled analgesia - who benefits? (Editorial) Anaesthesia 1997; 52: 401-2.

4 Mabler HIM, Kulik JA. Preferences for health care involvement, perceived control and surgical recovery: a prospective study. Soc Sci Med 1990; 31: 743-51.

5 Thomas $V$, Heath $M$, Rose D, Flory P. Psychological characteristics and the effectiveness of patient - controlled analgesia. Br J Anaesth 1995; 74: 271-6.

6 Brydon CW, Asbury AJ. Attitudes to pain and pain relief in adult surgical patients. Anaesthesia 1996; 51: 279-81.

7 Scott NB, Hodson M. Public perceptions of postoperative pain and its relief. Anaesthesia 1997; 52: 438-42.

8 Thomas VJ, Rose FD. Patient-controlled analgesia: a new method for old. J Adv Nursing 1993; 18 : 1719-26.

9 Thomas VJ, Heath $M L$, Rose FD. Effect of psychological variables and pain relief system on postoperative pain experience. (Abstract) Br J Anaesth 1990; 64: 388-9.

10 Johnson LR, Magnani B, Chan V, Ferrante FM. Modifiers of patient-controlled analgesia efficacy. 1 . Locus of control. Pain 1989; 39: 17-22.
11 Garden AL, Merry AF, Holland RL, Petrie KJ. Anaesthesia information - what patients want to know. Anaesth Intensive Care 1996; 24: 594-8.

12 Kluger MT, Owen H. Patients' expectations of patientcontrolled analgesia. Anaesthesia 1990; 45: 1072-4.

13 Klafta JM, Roizen MF. Current understanding of patients' attitudes toward and preparation for anaesthesia: a review. Anesth Analg 1996; 83: 1314-21.

14 Egbert LD, Battit GE, Welch CE, Bartlett $M K$. Reduction of postoperative pain by encouragement and instruction of patients. N Eng J Med 1964; 270: 825-7.

15 Anderson EA. Preoperative preparation for cardiac surgery facilitates recovery, reduces psychological distress, and reduces the incidence of acute postoperative hypertension. J Consult Clin Psychol 1987; 55: 513-20.

16 Wilder-Smith $\mathrm{CH}$, Schuler L. Postoperative analgesia: pain by choice? The influence of patient attitudes and patient education. Pain 1992; 50: 249-62.

17 Elsass P, Eikard B, Junge J, Lykke J, Staun P, FeldtRasmussen $M$. Psychological effect of detailed preanesthetic information. Acta Anaesthesiol Scand 1987; 31 : 579-83.

18 Williams $O A$. Patient knowledge of operative care. J R Soc Med 1993; 86: 328-31.

19 Keeri-Szanto M, Heaman S. Postoperative demand analgesia. Surgery, Gynaecology and Obstetrics 1972; 134: 645-51.

20 Taylor NM, Hall GM, Salmon P. Patients' experiences of patient-controlled analgesia. Anaesthesia 1996; 51: 525-8.

21 Taylor $N$, Hall GM, Salmon P. Is patient-controlled analgesia controlled by the patient? Soc Sci Med 1996; 43: 1137-43.

22 Owen H, McMillan V, Rogowski D. Postoperative pain therapy: a survey of patients' expectations and their experiences. Pain 1990; 41: 303-7. 